\title{
Prevalence and determinants of pain and pain-related disability in urban and rural settings in southeastern Ontario
}

\author{
Dean A Tripp $\mathrm{PhD}^{1}$, Elizabeth G VanDenKerkhof RN DrPH${ }^{2}$, Margo McAlister $\mathrm{BA}^{3}$
}

\begin{abstract}
DA Tripp, EG VanDenKerkhof, M McAlister. Prevalence and determinants of pain and pain-related disability in urban and rural settings in southeastern Ontario. Pain Res Manage 2006;11(4):225-233.
\end{abstract}

BACKGROUND: Canadian chronic pain prevalence estimates range from $11 \%$ to $66 \%$, are affected by sampling and measurement bias, and largely represent urban settings.

OBJECTIVES: To estimate chronic pain prevalence and factors associated with pain in southeastern Ontario, a region with a larger rural than urban residence.

METHODS: A systematic sampling with a random start was used to contact households. A telephone-administered questionnaire using the Graded Chronic Pain Scale, with questions on health care and medication use, health status, depression and demographics, was administered to consenting adults (18 to 94 years of age; mean age $50.2 \pm 16.6$ years).

RESULTS: The response rate was 49\% (1067 of 2167), with $76 \%$ reporting some pain over the past six months. Low pain intensity with low pain interference prevalence was 34\% (grade I), high pain intensity with low pain interference was 26\% (grade II), and high pain intensity with high pain interference was $17 \%$ (grades III and IV). Of those reporting pain, $49 \%$ reported chronic pain (ie, pain for a minimum of 90 days over the past six months) representing $37 \%$ of the sample. Being female, unmarried, lower income, poorer selfreported health status and rural residence were associated with increasing pain. Once depression was considered in this pain analysis, residence was no longer significant. Lower rates of health care utilization were reported by rural residents. In those reporting the highest pain grades, poor health, greater medication and health care use, depression and more pain sites were associated with higher odds for pain-related disability.

CONCLUSION: There is an elevated prevalence of pain in this almost equally split rural/urban region. Further examination of health care utilization and depression is suggested in chronic pain prevalence research.

Key Words: Chronic pain prevalence; Depression; Health care utilization; Rural Canada

\author{
La prévalence et les déterminants de la douleur \\ et des invalidités reliées à la douleur dans les \\ milieux urbains et ruraux du sud-est de l'Ontario
}

HISTORIQUE : Les estimations de la prévalence de la douleur chronique au Canada varient entre $11 \%$ et $66 \%$, sont entachées de biais d'échantillonnage et de mesures et représentent largement les milieux urbains.

OBJECTIFS : Estimer la prévalence de la douleur chronique et les facteurs associés à la douleur dans le sud-est de l'Ontario, une région où les résidents vivent davantage en milieu rural qu'urbain.

MÉTHODOLOGIE : On a utilisé un échantillonnage systématique associé à une date de début aléatoire pour prendre contact avec les ménages. Un questionnaire administré par téléphone faisant appel à l'échelle de la douleur chronique graduée, comportant des questions sur les soins de santé et l'usage des médicaments, l'état de santé, la dépression et la démographie, a été présenté à des adultes consentants (18 à 94 ans; âge moyen de $50,2 \pm 16,6$ ans).

RÉSULTATS : Le taux de réponse était de $49 \%$ (1 067 sur 2 167), $76 \%$ déclarant une certaine douleur au cours des six mois précédents. Une douleur de faible intensité associée à une faible interférence de la douleur s'observait dans $34 \%$ des cas (niveau I), une douleur de forte intensité associée à une faible interférence de la douleur, dans $26 \%$ des cas (niveau II), et une douleur de forte intensité associée à une forte interférence de la douleur, dans $7 \%$ des cas (niveaux III et IV). Chez ceux qui déclaraient ressentir de la douleur, $49 \%$ parlaient de douleurs chroniques (des douleurs pendant au moins 90 jours au cours des six mois précédents), représentant $37 \%$ de l'échantillonnage. Le fait d'être de sexe féminin, non marié, d'avoir un revenu relativement faible, un état de santé autodéclaré moins reluisant et d'habiter en milieu rural s'associait à une douleur grandissante. Lorsqu'on intégrait la dépression à cette analyse de la douleur, le lieu de résidence n'était plus significatif. Les résidents des régions rurales utilisaient moins les services de santé. Chez ceux qui déclaraient les niveaux de douleur les plus élevés, un plus grand usage des médicaments et des services de santé, une dépression et un plus grand nombre de foyers de douleur risquaient davantage de souffrir d'une invalidité reliée à la douleur.

CONCLUSION : La prévalence de la douleur est élevée dans cette région presque autant rurale qu'urbaine. Une analyse plus approfondie de l'utilisation des services de santé et de la dépression est proposée dans le domaine de la recherche sur la prévalence de la douleur chronique.

Dain prevalence estimates vary in the general population (1). In Ontario, chronic pain has a tremendous impact, not only on the individual, but also on society at large, with painrelated illness costing taxpayers five billion dollars annually (2). Chronic pain is also associated with behavioural effects such as reduced mobility and increased health care utilization, and psychological comorbidities such as depression (3).

Pain is regarded as a common experience, with approximately $80 \%$ of doctor visits associated with pain (2). However, inconsistency in measurement instruments, sampling techniques, study populations, the use of nonvalidated instruments and different definitions for chronic pain all contribute to the variability in pain estimates (4-6). Chronic pain reviews suggest the average population prevalence is $15 \%$, but international estimates can

${ }^{1}$ Departments of Psychology, Anesthesiology Eु Urology; ${ }^{2}$ Nursing, Anesthesiology, and Community Health Eु Epidemiology; ${ }^{3}$ Department of Psychology, Queen's University, Kingston, Ontario

Correspondence: Dr Dean A Tripp, Departments of Psychology, Anesthesiology Eु Urology, Humphrey Hall, 62 Arch Street, Queen's University, Kingston, Ontario K7L 3N6. Telephone 613-533-6955, fax 613-533-2499, e-mail dean.tripp@queensu.ca 
range from $2 \%$ to $40 \%$ (7) with Canadian estimates ranging from $11 \%$ to $66 \%(1,4,8-12)$. Although $77 \%$ of the Canadian population live in urban areas, these centres are geographically dispersed, creating large rural and rural/urban mixed regions. In Canada, rural health care is a salient concern because rural and urban environments may vary in culture, geography, economics, lifestyle, social organization and behaviours associated with illness and health care use.

To date, rural health care and chronic pain have received little empirical attention in Canada. The lack of rural/urban pain research is surprising, both because of Canada's significant rural population and because international studies show rural residents reporting higher pain prevalence. For example, there is little difference between rural and urban reports of annual income, quality of life or social support, but rural samples report higher pain frequency and intensity (13). Also, studies conducted in urban centres with better access to health care and chronic pain facilities may not reflect the epidemiology of pain and health care utilization patterns in predominantly rural regions (10). Indeed, George (14) found that after accounting for age and sex in his Saskatchewan-based sample, chronic low back pain was associated with being single, having mild low back pain six months before the baseline survey, reports of significant neck pain and a rural residency.

The association of pain and comorbid variables, such as depression, is not always examined in epidemiological chronic pain research. Depression is common with chronic pain and negatively impacts patient adjustment (15). Pain that interferes with activities of daily living is associated with significant depression; as many as $65 \%$ of patients with depression report persistent pain, and a wide range of chronic pain patients report comorbid depression ( $5 \%$ to $85 \%$ ) (15). It is important to document the association of depression and chronic pain in communities because generally speaking, depression is regarded to be a treatment-responsive affective disorder (16). Indeed, when comorbid depression is treated, patients with pain report improvements in pain intensity, functional status and quality of life (17).

In summary, chronic pain is a health care issue in Canada, but many regions are not adequately represented in the present prevalence statistics and little is known about what variables may best account for elevated pain. The research plan of the present study was to use validated instruments to estimate the prevalence of chronic pain and its associated factors in a rural/urban region of southeastern Ontario (ie, sex, marital status, area of residence, years of school, annual income, health care/medication use and health status). Depression was also assessed to explore its impact when collected with routinely referenced pain prevalence factors. Self-ratings of health are important in prevalence studies because they are a simple but effective method of attaining information about general health and are widely used in population surveys $(18,19)$.

The general aim of our study was to document the prevalence of chronic pain in the southeastern region of Ontario and to examine if pain report is predicted by variables detailed in previous research (eg, age, residence, income and health status). There were three primary hypotheses examined:

1. It was hypothesized that this sample would report chronic pain comparable with that reported in other studies using similar pain definitions and pain-grading methodology (ie, higher grades of pain to be more frequent in females, older age groups, rural residents and those of lower socioeconomic status). As well, the present study sought to explore the influence of depression by rerunning the previous analysis controlling for depression as an additional independent variable.

2. It was hypothesized that rural residents would report less health care utilization than urban residents.

3. As a final hypothesis, participants reporting the higher pain grades (grades III and IV) would be more likely to report higher health care utilization, medication consumption (20) and a rural residence $(13,14)$.

\section{Participants}

\section{METHODS}

Queen's University Ethics Board (Kingston, Ontario) approval was obtained to interview adults 18 years of age and older residing in several counties in southeastern Ontario: Frontenac, Lennox and Addington, Hastings, Lanark, Leeds-Grenville, Northumberland and Prince Edward. Based on 2001 Census data (21), approximately 422,410 individuals 20 years and older resided in this area. Sample size calculations were based on findings in Canadian studies utilizing telephone surveys and a validated questionnaire such as the Graded Chronic Pain Scale (GCPS) (1,9-11). Assuming a pain prevalence of $44 \%$, a sample of 1049 would produce an estimate within $\pm 3 \%$ points of the true population prevalence, 19 times out of 20 (95\% CI) (22).

\section{Sampling method}

A systematic sampling with a random start was used to contact households. The sampling frame included residents listed in telephone directories for the region. Directories contained approximately the same number of entries per page, therefore, a proportional number of residences were chosen from each directory. Using a random number table, it was determined that the telephone number $12 \mathrm{~cm}$ down from the first entry in the column was to be selected from the first and third column on each page. If the number was a business or was disconnected, the callers moved on to the next number in the series. If the number dialled was a residence, there was no answer, or a busy signal, the number was attempted again an hour later during that calling session or into the next calling session if the call back time extended beyond the session, to a maximum of three call back attempts. If no contact was initiated or the contact refused to participate, the number directly below was selected until a participant was recruited. When a successful connection was made with an adult older than 18 years of age who was a resident of the household, the volunteer proceeded with the interview. However, if the person was younger than 18 years of age or not a resident of the house, the interviewer recorded a better time to call back later. Once contact was made, the volunteers interviewed the participant using a scripted $10 \mathrm{~min}$ questionnaire. This method resulted in the identification of 1215 telephone numbers but recruitment stopped after 1069 participants. Interviews were conducted by Queen's University students who were trained and monitored by the research coordinator. Calls were conducted Sunday to Thursday evenings between 17:00 and 21:00 over four consecutive weeks in January and February 2004.

\section{Residence}

The present study used Statistics Canada classification for Census Subdivision (23) which is the general term for municipalities, as 
determined by provincial legislation, for statistical purposes. Census subdivisions are classified into 46 types according to official designations adopted by provincial or federal authorities. The census subdivision type accompanies the census subdivision name to distinguish, for example, towns from townships with the same name. The census subdivision types found in the study region were Township, Town and City. Townships, which represent largely rural districts, were considered to be 'rural', Towns to be 'town' and City to be 'urban'.

\section{Measures}

A scripted 10 min telephone questionnaire was created for data collection. Demographic information, including questions about self-rated general health and socioeconomic status (measured by annual income and education level) were also included in the questionnaire.

Chronic pain was measured using the seven-item GCPS $(20,24)$. The GCPS measures pain on a continuum defined by intensity and interference. Lower pain grading levels (grades I and II) are differentiated by pain intensity (low versus high), and the higher pain grades (grades III and IV) are differentiated from the lower grades primarily by the increased disability or interference with activities in their life. The GCPS includes three 11-point scales of pain intensity $(0=$ no pain; $10=$ pain as bad as could be $)$. Similarly, the GCPS contains items assessing disability or interference with daily activities, social and family activities, and interference with usual activities such as work $(0=$ no interference; $10=$ unable to carry on any activities). The number of disability days, or days the respondent has been kept from daily activities, is also included in the GCPS. The five grades of the GCPS are: grade 0: no pain problem; grade I: low interference-low intensity; grade II: low interference-high intensity; grade III: high interferencemoderately limiting; and grade IV: high interference-severely limiting. Pain persistence, or the number of days pain has been experienced over the past six months, is not used in assigning a pain grade but is included in the questionnaire to provide information supplementing the pain grade (20). The internal consistency in the present study was 0.84 for patients with back pain, 0.79 for patients with headache and 0.84 for patients with temporomandibular disorder pain. Reductions in pain severity in grades I and II requires a reduction in intensity, while reduction in pain severity in grades III and IV can be accomplished through decreased disability even if pain intensity is not reduced (5).

Depressive symptoms were screened with the short version of the Primary Care Evaluation of Mental Disorders Patient Health Questionnaire (PHQ) (25). This questionnaire was chosen because it is efficient and easy to administer over the telephone. The PHQ is based on the criteria of the Diagnostic and Statistical Manual of Mental Disorders, Fourth Edition (26), and has been tested for validity in screening for major depressive disorders (25). The PHQ contains nine questions, each beginning with, "Over the last 2 weeks, how often have you been bothered by..." and ending with four possible choices: 'not at all', 'several days', 'more than half the days' or 'nearly every day'. Depressive status indicator was screened and classified as 'no depressive disorder', 'other depressive disorder' or 'major depressive disorder'. The internal consistency in the present study was 0.74 . The PHQ has diagnostic validity comparable to the Primary Care Evaluation of Mental Disorders, and it agrees with diagnoses provided by interviews with independent mental health professionals (25).
Health care utilization was assessed by questions related to health care visits. Participants were asked, "Over the last six months, have you seen any doctors, specialists, or other professionals for your (anatomical site) pain?" and number of visits over the past six months were recorded. Medication use was measured by asking, "Are you currently using any medication (over-thecounter or prescribed) for your pain?" and interviewers recorded the number of times this medication was taken weekly. The questionnaire also included an open-ended question, "Are there any other ways besides medication you have tried to reduce your pain?" to gather information on alternative pain-relief techniques.

\section{Analyses}

Analyses were primarily based on the above hypotheses. The first hypothesis examined the prediction of pain grading across all participants (ie, pain grade 0 [no pain] through pain grades I to IV). The primary outcome measure of pain grade was analyzed as an ordinal variable in bivariate analysis using the gamma statistic, and in multivariable analysis using ordinal regression to predict overall pain report. Due to the potential strong effect that depression is suggested to have on pain, the pain analysis was conducted with and without the depression variable to explore its impact on pain prediction. The second hypothesis, conducted on the subgroup of participants reporting pain (grades I to IV), assessed differences in number of health care visits by area of residence for participants experiencing increasing levels of pain interference. This analysis was examined using univariate general linear modelling to control for age, sex, marital status, depression and self-rated health status, while assessing for an interaction effect between area of residence and chronic pain grade. The final hypothesis, that higher pain grades would be associated with greater health care utilization, medication use and rural residence, was also conducted on the subgroup of participants reporting pain (grades I to IV). For the purpose of this subgroup analysis, the pain grade score was dichotomized into low life-related interference (grades I and II) and high interference (grades III and IV). $\chi^{2}$ and logistic regression were used to estimate factors associated with higher pain grades. An alpha level of 0.05 was used for all statistical tests. Preliminary model entry was set at $\mathrm{P} \leq 0.25$ and model stay was set at $\mathrm{P} \leq 0.05$. Model fit was assessed using the Hosmer and Lemeshow test and the -2 Log Likelihood Ratio test. Area of residence was assigned according to Statistics Canada classification for census data. Depressive disorder was calculated using the PHQ algorithm (25). Statistical analyses were carried out using SPSS version 12.0 (SPSS Inc, USA).

\section{RESULTS}

A total of 3237 telephone numbers were dialled, with 2167 successful contacts, yielding a contact rate of $78 \%$. Of the 2167 successful contacts, 1067 participated in the survey, producing a response rate of $49 \%$. Descriptive statistics are in Table 1. Fifty-three per cent of the participants were women, the mean age was $50.2 \pm 16.6$ years, and the majority were married (59\%) with at least 14 years of education (50\%). Approximately $15 \%$ of the sample reported symptoms of depression. Compared with the Canadian population, this sample was older and consisted of more women, rural residents and respondents with lower income.

\section{Pain prevalence and prediction}

Twenty-four per cent of respondents reported no pain (Table 2), $60 \%$ reported low to high pain intensity with low pain-related 
TABLE 1

Baseline characteristics of study participants

\begin{tabular}{|c|c|c|c|c|}
\hline & \multicolumn{2}{|c|}{ Study } & \multicolumn{2}{|c|}{ Census* $(\%)$} \\
\hline & $\mathbf{n}$ & $\%$ & $\operatorname{Region}^{\dagger}$ & Canada \\
\hline \multicolumn{5}{|l|}{ Age, years ${ }^{\ddagger}$} \\
\hline $20-24$ & 41 & 4 & 8 & 9 \\
\hline $25-34$ & 136 & 13 & 16 & 18 \\
\hline $35-44$ & 216 & 21 & 22 & 22 \\
\hline $45-54$ & 244 & 23 & 20 & 20 \\
\hline $55-64$ & 174 & 17 & 14 & 14 \\
\hline $65-74$ & 126 & 12 & 11 & 9 \\
\hline $75+$ & 103 & 10 & 9 & 8 \\
\hline \multicolumn{5}{|l|}{ Sex } \\
\hline Male & 491 & 46 & 48 & 49.5 \\
\hline Female & 570 & 53 & 52 & 50.5 \\
\hline \multicolumn{5}{|l|}{ Marital status } \\
\hline Single & 164 & 15 & 26 & 31 \\
\hline Married & 635 & 59 & 50 & 45 \\
\hline Separated & 38 & 4 & 3 & 3 \\
\hline Divorced & 74 & 7 & 7 & 7 \\
\hline Widowed & 89 & 8 & 7 & 6 \\
\hline Common law & 57 & 5 & 7 & 9 \\
\hline Other/not stated & 9 & 1 & - & - \\
\hline \multicolumn{5}{|l|}{ Location of residence ${ }^{\S}$} \\
\hline Rural & 585 & 55 & 46 & 20 \\
\hline Urban & 482 & 45 & 54 & 80 \\
\hline \multicolumn{5}{|l|}{ Self-rated health } \\
\hline Excellent & 298 & 28 & & \\
\hline Good & 516 & 49 & 53 & 57 \\
\hline Fair & 188 & 18 & & \\
\hline Poor & 52 & 4.9 & 47 & 43 \\
\hline \multicolumn{5}{|l|}{ Years of school** } \\
\hline $0-8$ & 185 & 15 & & \\
\hline $9-13$ & 411 & 34 & & \\
\hline $14-17$ & 452 & 38 & & \\
\hline $18+$ & 149 & 12 & & \\
\hline \multicolumn{5}{|l|}{ Average annual income ${ }^{* \star}$} \\
\hline$<20,000$ & 187 & 17 & & \\
\hline 20,000 to 39,999 & 285 & 27 & & \\
\hline 40,000 to 79,999 & 308 & 29 & & \\
\hline$\geq 80,000$ & 93 & 9 & & \\
\hline Not revealed & 193 & 18 & & \\
\hline \multicolumn{5}{|l|}{ Depression } \\
\hline No symptoms & 861 & 85 & & \\
\hline Other depressive disorder & 88 & 8.7 & & \\
\hline Major depressive disorder & 60 & 5.9 & & \\
\hline
\end{tabular}

Frequencies do not add up to 1067 due to missing data and percentages may not sum to 100 due to rounding. *Comparison based on 2001 Census data; ${ }^{\dagger}$ Region includes southeastern Ontario counties Frontenac, Lennox and Addington, Northumberland, Hastings, Prince Edward, Leeds, Grenville, and Lanark District Health Regions; ¥Participants aged 18 to 19 years were excluded from percentage calculations because census data were broken down by five-year intervals; §Canadian Census data were not broken down at the national level by town, rural and urban, therefore for the purpose of the comparison with Canadian Census data, these three categories were grouped together as rural. This likely explains the higher rural distribution in our study relative to the Census data; "Census data includes respondents aged 12 and over, and collapses categorizes into good/excellent and poor/fair; **Education and income categories not available from Census statistics using these breakdowns
TABLE 2

Description of pain prevalence using the Graded Chronic Pain Scale (GCPS) categories and individual measures of intensity, disability and chronicity

\begin{tabular}{lcc}
\hline Grade (n=1058) & $\mathbf{n}$ & $\%$ \\
\hline 0 - No pain problem & 252 & 24 \\
I - Low intensity/low interference & 359 & 34 \\
II - High intensity/low interference & 272 & 26 \\
III - Moderately limiting/high interference & 90 & 8.5 \\
IV - Severely limiting/high interference & 85 & 8.0 \\
Chronicity classification & & \\
Participants reporting GCPS = I to IV (n=799) & $\mathbf{n}$ & $\%$ \\
\hline Nonpersistent pain (<90 days) & 406 & 51 \\
Persistent pain ( $\geq 90$ days) & 393 & 49 \\
Pain characteristics & Median (mean) & $\mathbf{( 2 5 \% , 7 5 \% )}$ \\
\hline Characteristic pain intensity (/10) & $5(5)$ & $3.7,6.3$ \\
Pain days over past six months & $72(92)$ & 20,180 \\
Disability days over past six months & $0(12)$ & $0.0,2.0$ \\
Disability score (/100) & $23(32)$ & $6.7,53$ \\
\hline
\end{tabular}

Chronicity classification data are missing for seven of the 806 individuals reporting pain level $\geq 1$

life interference (grades I to II), and approximately $16 \%$ reported high pain intensity with moderate to highly limiting pain with high life interference. Sensitivity analysis suggested that if all survey nonresponders reported 'no pain', pain prevalence would have been $38 \%$ in the present study. However, if all nonresponders did report some grade of pain, the prevalence would have been $88 \%$ in the present study. Close to one-half of participants reported chronic pain (49\%; persisting at least 90 days over past six months). The mean characteristic pain intensity for all respondents with pain was $5 / 10$, with quartile ranges of 3.7/10 (25th) and 6.3/10 (75th). The median number of pain days reported over the previous six months was 72 days, with quartile ranges of 20 (25th) and 180 days (75th) and the median number of disability days was 0 with quartile ranges of 6.7 (25th) and 53 days (75th).

In bivariate analyses, sex, area of residence, self-rated health, years of school and annual income were individually associated with pain grades $(\mathrm{P}<0.05$; Table 3$)$. The distribution of residence by pain grade revealed increasing severity of pain with decreasing population density. Age was also investigated for its effect on pain report. Age was plotted against pain grade score (Figure 1). Age was divided into three categories for the purpose of the present analysis, reflecting younger, middle-aged and older participants as conducted in similar Canadian epidemiological research (11). Analysis showed significantly higher levels of pain and interference in the 35- to 64-year-old age group $\left(\chi^{2}=18.7, P=0.02\right)$. This age group was four times more likely to report pain grade score of IV than those 18 to 34 years of age, and two times more likely to report a pain grade score of IV than participants aged 65 years or older. In a multivariable analysis that examined only the significant bivariate variables, being female, having a rural residence, reporting a lower health status and lower income were associated with higher pain grades (Table 3 ).

Due to the authors' interest in exploring the effects of comorbid depression on pain report, the same variables included 
TABLE 3

Bivariate factors related to pain and multivariable follow-up analyses using the Graded Chronic Pain Scale ( $n=1058)$

\begin{tabular}{|c|c|c|c|c|c|c|c|c|}
\hline Mean age $\pm S D$ & 1052 & $51 \pm 17$ & $50 \pm 17$ & $49 \pm 17$ & $50 \pm 18$ & $51 \pm 13$ & $F=0.49(0.74)$ & \\
\hline Male & 487 & 28 & 38 & 22 & 5.7 & 6.4 & $-0.23(<0.01)$ & ---- \\
\hline Female & 565 & 20 & 30 & 29 & 11 & 9.6 & & $0.29(<0.01)$ \\
\hline $\begin{array}{l}\text { Married or } \\
\text { common law }\end{array}$ & 1048 & & & & & & & \\
\hline Yes & 685 & 25 & 35 & 26 & 7.6 & 7.7 & $-0.06(0.22)$ & \\
\hline No & 363 & 23 & 33 & 25 & 11 & 8.5 & & \\
\hline Area of residence & 1058 & & & & & & & \\
\hline Rural $^{\dagger}$ & 261 & 20 & 36 & 25 & 7.7 & 11 & & $0.21(<0.01)$ \\
\hline Town & 319 & 24 & 30 & 28 & 8.8 & 9.1 & $-0.08(0.03)$ & $0.13(<0.10)$ \\
\hline Fair & 188 & 6.4 & 28 & 35 & 16 & 14 & & $-1.8(<0.01)$ \\
\hline Poor & 52 & 0.0 & 9.6 & 19 & 17 & 54 & & $-1.0(<0.01)$ \\
\hline Years of school & 1051 & & & & & & & \\
\hline$<14$ & 450 & 22 & 30 & 28 & 8.7 & 11 & & \\
\hline$\geq 14$ & 601 & 25 & 37 & 24 & 8.3 & 6.0 & $-0.14(<0.01)$ & NS in final model \\
\hline Annual income & 1043 & & & & & & & \\
\hline$<\$ 20,000$ & 185 & 15 & 29 & 30 & 10 & 16 & & $0.16(<0.17)$ \\
\hline$\$ 20,000$ to $\$ 39,999$ & 284 & 25 & 34 & 27 & 8.5 & 6.3 & & $-0.15(<0.15)$ \\
\hline$\$ 40,000$ to $\$ 79,999$ & 305 & 26 & 38 & 24 & 6.9 & 5.2 & $-0.10(<0.01)$ & $-0.18(<0.08)$ \\
\hline$\geq \$ 80,000$ & 92 & 36 & 38 & 16 & 5.4 & 4.3 & & $-0.38(<0.01)$ \\
\hline
\end{tabular}

Due to missing data in the bivariate analyses the individual sample size is reduced from 1058; due to missing data the sample size is reduced to 1049 in the multivariable analyses. ${ }^{*}$ Age and marital status were excluded from the multivariable model $(P>0.05) ;{ }^{\dagger}$ Rural includes Statistics Canada Census classification for village and township; Multivariable analysis conducted using probit link function; Pearson goodness-of-fit $\chi^{2}=420$, degrees of freedom $=442$, $P=0.77$; Nagelkerke pseudo $R^{2}=0.23$. --- Variable was used as a reference category in the mulitvariable analysis; NS Not significant

in the multivariable analysis in Table 3 were examined, but included depression. This analysis showed depression had a significant association to pain grade (reference category: major depressive disorder; no depression: $\beta=-0.97, \mathrm{P}<0.01$; mild depression: $\beta=-0.47, P<0.02$ ). The addition of depression did not remove any previously significant variables, except for area of residence, which was no longer associated with pain grade with depression added to the multivariable model (reference category: urban; rural: $\beta=0.11, P=0.20$; town: $\beta=0.04$, $\mathrm{P}=0.60)$.

Health care utilization

An analysis was conducted for only those respondents reporting pain grade scores of I to IV. There is a statistically significant difference in number of health care visits over the past six months by pain grade and area of residence $(F=2.3$, $\mathrm{P}=0.02$ ). After controlling for age, sex, marital status, depression and self-rated health, participants reporting high pain interference were more likely to visit health care providers if they lived in urban or town versus rural settings (Figure 2). Only the interaction between area of residence and pain grade remained significant in the final model. The model accounted for $23 \%$ of the variation in number of health care visits, indi-

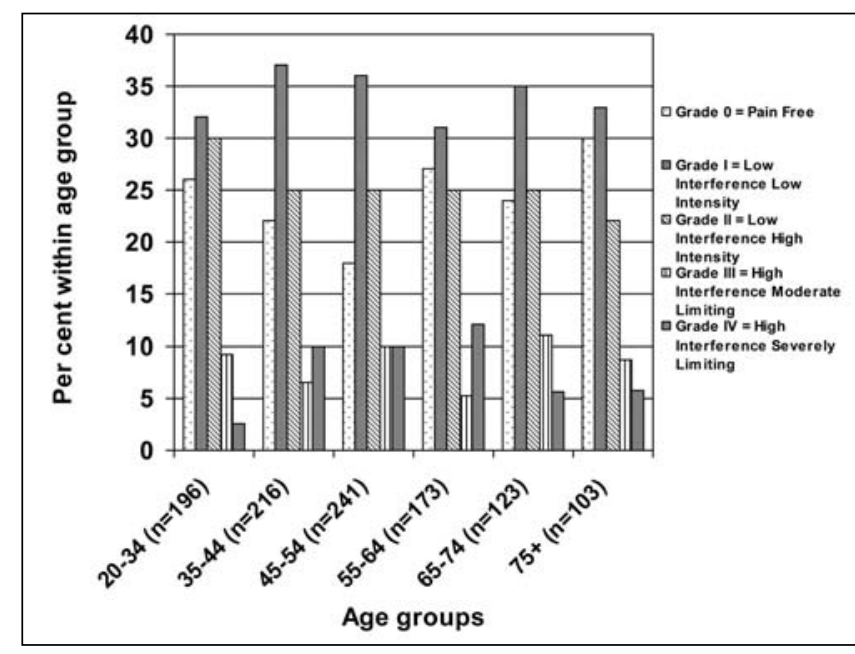

Figure 1) Percentage distribution of the Graded Chronic Pain Scale scores by age category (years) $(n=1052)$

cating that they are significant unaccounted for factors. Detailed analysis of health care visits by pain grade revealed that respondents reporting high pain interference (grade IV) 


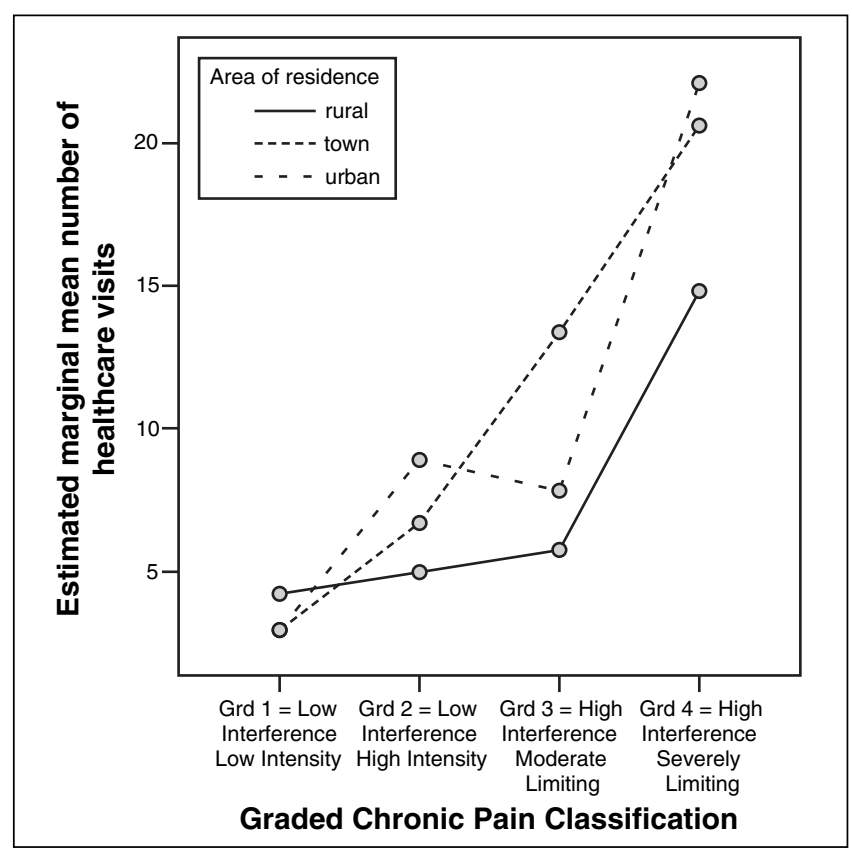

Figure 2) Health care visits by Graded Chronic Pain Scale and area of residence $(n=804)$. Grd Grade

living in town and urban settings were more likely to visit medical practitioners and allied health professionals than rural respondents reporting pain grade IV.

\section{Pain subgroup prediction}

Pain was categorized into low (grades I to II) versus high (grades III to IV) (Table 4). No statistically significant twoway interactions were found, so the final model included main effects only. Health status, medication use, health care utilization, depressive symptoms and number of pain sites were associated with higher pain grades, which are defined by their increasing level of life interference. Respondents who reported fair to poor health were 2.3 times more likely to report high pain than respondents who reported good to excellent health (95\% CI 1.5 to 3.6; $\mathrm{P}<0.01$ ). Respondents reporting using medications more than six times per week were 2.6 times more likely to report high pain than those reporting no medication use $(95 \%$ CI 1.5 to $4.3 ; \mathrm{P}<0.01)$. Respondents reporting greater than six health care visits over the previous six months were four times more likely to report high pain than those reporting no visits (95\% CI 2.9 to 8.4; $\mathrm{P}<0.01$ ). Respondents indicating major depressive disorder were 4.5 times more likely to report high pain than those reporting no depressive symptoms $(95 \%$ CI 2.2 to $9.3 ; \mathrm{P}<0.01)$. Finally, respondents reporting five or more pain sites were 4.5 times more likely to report high pain than those reporting one pain site (95\% CI 2.2 to 9.0; $\mathrm{P}<0.01)$.

\section{DISCUSSION}

Seventy-six per cent of participants reported some level of pain (GCPS grades I to IV), while $42 \%$ of the sample reported high pain and increasing limitations from their pain (GCPS grades II to IV). Forty-nine per cent of participants with pain reported chronic pain (pain for at least 90 days over the past six months), representing $37 \%$ of this sample. Among other variables (sex, health status and income), residence was found to be associated with worsening pain grades. However, after controlling for depression, there was no longer a statistically significant association between residence and pain grade. In the two subgroup analyses, which only included participants reporting pain (grades I to IV), when age, sex, marital status, depression and health were controlled, a rural residence was associated with less health care utilization. As well, lower health status, greater medication use, greater health care visits, depression and greater number of pain sites were associated with high pain interference (grades III and IV).

The present prevalence estimate of $76 \%$, where respondents reported pain and varied levels of life interference, is high compared with other studies (11\% to $66 \%[4,8,10-12]$ ). This is most likely due to the inclusion of mild pain with low life interference. By listing common pain conditions such as headache, joint pain and stomach pain, and asking participants to report on the most bothersome condition, the present pain grades of the GCPS likely captured pain not assessed by less-detailed pain assessment tools (4). The more conservative pain prevalence estimate in the present study (ie, $42 \%$; GCPS grades II to IV) is consistent with or higher than other Canadian studies using either a validated questionnaire $(1,9)$ or a lengthy reference period $(10,11)$. For example, Birse and Lander (10) reported a moderate-high prevalence of $44 \%$ of recurrent or persistent pain of six months duration, while Moulin et al (11) reported a prevalence of 29\% using a definition of intermittent or continuous pain present for at least six months. In contrast, in a random sample of Ontario residents, Crook et al (12) reported a prevalence of $11 \%$ when asking about pain over the past two weeks. In our study, a validated pain questionnaire captured not only pain intensity, but pain-related interference, thereby providing a measure of the impact of pain on daily activities.

One of the major findings in our study was that a rural residence was influential in predicting pain grade in those reporting any pain. This is consistent with findings presented by Hoffman et al (13) and suggests that greater pain may be more commonplace in rural versus urban settings. However, by exploring the effects of a validated depression screening questionnaire on the prediction of pain grades ( 0 to IV), this study also found that the burden of depression has a stronger association with pain than area of residence in the total sample. These findings indicate that depression is perhaps a more salient variable to consider when examining pain across rural and urban residents, because it impacts pain grades regardless of area of residence.

The cross-sectional nature of the present study provides no insight into the directionality of the depression and pain relationship. It is important to note that there was a strong positive relationship between pain level and depression, with almost one-half of participants who reported major depression also reporting severely limiting pain with high pain-related life interference. These findings are consistent with the pain and depression literature where the majority of depressed patients report significant pain and a wide range of chronic pain patients present with comorbid depression (5\% to 85\%) (15). Furthermore, higher pain intensity and life interference was one of the most robust associations with higher levels of depression (along with increasing number of pain sites). It is clear from these data that depression is a significant factor in the pain prevalence reported for southeastern Ontario. Perhaps these data indicate that future pain prevalence studies 
TABLE 4

Factors associated with high pain-related interference for respondents reporting any pain using the Graded Chronic Pain Scale, in bivariate and multivariable logistic regression analyses

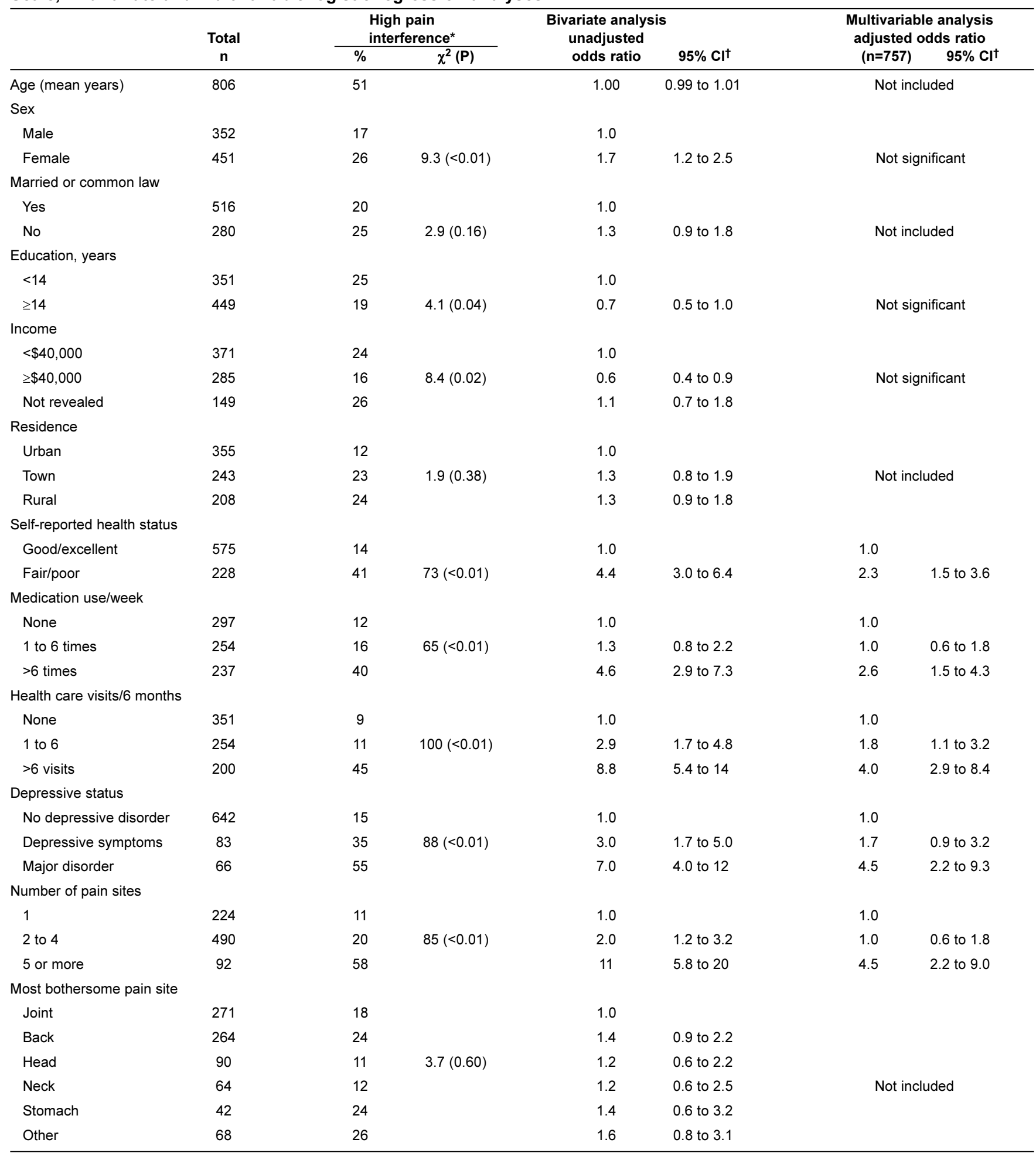

${ }^{*}$ High pain-related interference (grades III and IV); ${ }^{\dagger}$ Model fit -2 Log Likelihood ratio test $=569$, removal of any further variables would have resulted in a significant change in the model; Hosmer and Lemeshow $\chi^{2}=8.8,(P=0.36)$

should focus on the effects that depression may have on other chronic pain factors such as sex, marital status, area of residence, years of school and annual income, health care/medication use and/or medical status.
Our bivariate analyses showed that common associated pain factors, such as sex $(11,18,27)$, marital status (28), income (24) and health status (29) were associated with increasing levels of pain in the present study. Older age is 
frequently associated with pain $(11,18)$, however, there was no association between mean age and pain grade. The highest reported level of pain and pain-related life interference was found in the 35- to 64-year-old age group, which may be reflective of the impact that pain has on workforce participation of this group. Age is negatively associated with pain severity and pain interference but positively related to perceived control and the possibility of presenting with a pain diagnosis (30). It is suggested that as people age, their life context (eg, not working) places restrictions on daily opportunities for pain experience. Further research is necessary to clarify such associations among pain, interference and age.

In the present data, a rural residence was associated with a significant decrease in self-reported health care visits over the past six months as pain grade increased. After controlling for covariates, including depression, there was an interaction between pain grade and residence, where participants reporting high pain interference in urban regions or towns were more likely to seek health care than those in rural regions. This model accounted for $23 \%$ of the variation in number of health care visits, indicating that there are significant unaccounted for factors yet to be included in such an analysis. Perhaps for rural participants the decreased health care visits are a product of resource location and access compared with urban participants, or that rural participants tend to self-manage pain for longer periods of time. The data collected in the present study do not allow for a clear delineation of why rural residents are reporting less frequent health care visitation. Clearly, this should be addressed in future surveys using direct inquiry from participants.

Only $50 \%$ of respondents reporting low pain interference and $17 \%$ reporting high interference consulted health care practitioners over the previous six months. Similar results were noted by Catala et al (27) and Crook et al (12). In the present study, reduced health care utilization may be related to the rural nature of the region, where transportation or the opportunity to access health care facilities may impede service delivery. The southeastern Ontario region does not have a centralized, public access, multidisciplinary pain clinic and has been primarily serviced by an anaesthesiologist providing parttime consultations. However, in southeastern Ontario, many patients with chronic pain are managed by community-based family physicians. Past treatment failure may also contribute to these health care trends but the present study did not collect that information and cannot address this question. Future research should examine the relations of pain, medication use and health care utilization in rural Canadian regions where access may exert influence on use.

Participants reporting the highest pain grades were more likely to report poorer health, increased medication use, higher rates of health care utilization, greater depressive symptoms and a larger number of pain sites. The association between chronic pain and health care visits and medication use was consistent with the literature (18). Chronic pain patients also report high rates of both analgesic consumption and health care utilization (31), show large differences in health care utilization between pain involving low disability versus high disability (24), and medication usage is 1.5 times more likely if disability is salient (32). The present data may reflect attempts to decrease pain-related interference through medication use and consultation with health care practitioners but further research is required to validate these self-reported findings or to substantiate a revision of current health care practices in this region.

A major issue in Canada's health care system is our country's vast and isolated rural communities and the fact that many are medically and psychologically underserviced. Rural health care may be an especially important topic when geographically isolated minorities are considered. Several health issues exist at far greater prevalences for Canada's First Nations peoples than in the total Canadian population (ie, depression, suicide and substance abuse) (33). As noted in the present study, depression may be a more salient predictor of chronic pain over area of residence but there are no data, that we are aware of, that document prevalence and comorbid predictors of chronic pain for the Canadian First Nations population.

Response bias may have contributed to the high prevalence of pain in the present study; however, even if all nonresponders were assumed to have no pain, the pain prevalence (ie, 37\%) remains within the higher range of Canadian estimates in the literature. This would suggest that southeastern Ontario may have a higher prevalence of pain than other samples from the Canadian population. The present findings may not be solely reflective of life in rural regions but may be due to the higher proportion of women and older persons living in this region, as reported by both our study and Canadian Census data. Further research is required to determine if these findings are unique to this region or to rural Canadian regions in general. Given that studies in the literature are primarily centred on large urban areas or comprise a random sample of the population where characteristics of large urban centres overshadow characteristics of smaller rural populations, it is not surprising that the present findings differ from some of the current pain prevalence data.

Study limitations include response rate, sampling method and the representativeness of the sample, and the generalizability of the findings. Although the response rate of $49 \%$ compares with rates for similar studies $(19 \%$ to $69 \%)(10,11)$, response behaviour could have opposing effects on these results. For example, individuals in pain may have been more interested and thus more likely to participate in the present study, but pain-related interference may also have made it less likely that people in pain actually answered the phone and participated. Furthermore, the exclusion of residents in nursing homes and other institutions where pain is likely to be elevated could contribute to a conservative prevalence estimate in this region.

The sampling method used in the present study was not truly random because a phone directory was used rather than random digit dialling, which has a nonzero probability of selecting cellular phones and unlisted lines; numbers were dialled between 17:00 and 21:00 rather than throughout the day; and the respondent was not randomly selected as in studies in which the person with the most recent birthday is recruited. These three deviations from random sampling may partly explain why this sample over-represents the regional Census data for those older than 35 years of age and married. Perhaps these people are more likely to be home in the evening hours than younger or single people. Although the sampling method used does present issues, the use of a random digit dialling system or access to a staff of daytime callers was not feasible in the present study. However, the inclusion of cellular telephone numbers would have resulted in some households having higher odds of being selected into the 
study (ie, may have one land line and several cellular telephones in a household).

The representativeness of the sample, assessed by comparing the demographic profile of participants with the 2001 Canadian Census data for southeastern Ontario, showed that age, sex and urban-rural distributions of the study sample (55\% rural) were comparable with the distributions captured in the census data (46\% rural). However, both the rural distribution in the present study (55\%) and the regional Census statistics $(46 \%)$ are elevated compared with Canadian population Census figure (20\% rural). Thus, perhaps these are legitimate differences due to the rural nature of this area rather than sampling error. Hence, it is possible that the present study's

\section{REFERENCES}

1. Elliott AM, Smith BH, Penny KI, Smith WC, Chambers WA. The epidemiology of chronic pain in the community. Lancet 1999;354:1248-52.

2. Canadian Pain Consortium. Canadian Consortium on Pain Mechanism Diagnosis and Management. Final Report 2001. $<$ www.curepain.ca/final.htm> (Version current at November 2, 2006).

3. Breen J. Transitions in the concept of chronic pain. ANS Adv Nurs Sci 2002;24:48-59.

4. Van Den Kerkhof EG, Hopman WM, Towheed TE, Anastassiades TP, Goldstein DH, Canadian Multicentre Osteoporosis Study Research Group. The impact of sampling and measurement on the prevalence of self-reported pain in Canada. Pain Res Manage 2003;8:157-63.

5. Von Korff M. Epidemiological and survey methods: Assessment of chronic pain. In: Turk DC, Melzack R, eds. Handbook of Pain Assessment. New York: The Guilford Press, 2001:603-18.

6. Macrae WA, Davies HT. Chronic postsurgical pain. In: Crombie IK, Croft PR, Linton SJ, SeResche L, Von Korff M, eds. Epidemiology of Pain. Seattle: IASP Press, 1999:125-42.

7. Verhaak PF, Kerssens JJ, Dekker J, Sorbi MJ, Bensing JM. Prevalence of chronic benign pain disorder among adults: A review of the literature. Pain 1998;77:231-9.

8. Millar WJ. Chronic pain. Health Rep 1996;7:47-53.

9. Elliott AM, Smith BH, Smith WC, Chambers WA. Changes in chronic pain severity over time: The Chronic Pain Grade as a valid measure. Pain 2000;88:303-8.

10. Birse TM, Lander J. Prevalence of chronic pain. Can J Public Health 1998;89:129-31.

11. Moulin DE, Clark AJ, Speechley M, Morley-Forster PK. Chronic pain in Canada - Prevalence, treatment, impact and the role of opioid analgesia. Pain Res Manage 2002;7:179-84.

12. Crook J, Rideout E, Browne G. The prevalence of pain complaints in a general population. Pain 1984;18:299-314.

13. Hoffman PK, Meier BP, Council JR. A comparison of chronic pain between an urban and rural population. J Community Health Nurs 2002;19:213-24.

14. George C. The six-month incidence of clinically significant low back pain in the Saskatchewan adult population. Spine 2002;27:1778-82.

15. Bair MJ, Robinson RL, Katon W, Kroenke K. Depression and pain comorbidity: A literature review. Arch Intern Med 2003;163:2433-45.

16. Roth A, Fongay P. What Works for Whom? A Critical Review of Psychotherapy Research, 2nd edn. New York: Guilford Press, 2005.

17. Lin EH, Katon W, Von Korff M, et al. Effect of improving depression care on pain and functional outcomes among older adults with arthritis: A randomized controlled trial. JAMA 2003;290:2428-9 findings do provide a unique perspective on the prevalence of pain, pain-related interference and health care utilization in one area of Canada with a mixed rural and urban population.

ACKNOWLEDGEMENTS: The authors gratefully acknowledge the contribution of the study participants, the Queen's University Psychology Department student volunteers who assisted with data collection, and the Kingston General Hospital for providing a call centre. They also thank the reviewers for their excellent comments on the manuscript.

FUNDING: The study was supported in part by a Queen's University Advisory Research Committee grant.

18. Blyth FM, March LM, Brnabic AJ, Jorm LR, Williamson M, Cousins MJ. Chronic pain in Australia: A prevalence study. Pain 2001;89:127-34.

19. Smith BH, Elliott AM, Chambers WA, Smith WC, Hannaford PC, Penny K. The impact of chronic pain in the community. Fam Pract 2001;18:292-9.

20. Von Korff M, Dworkin SF, Le Resche L. Graded chronic pain status: An epidemiologic evaluation. Pain 1990;40:279-91.

21. Statistics Canada. 2001 Census of Canada. $<$ www12.statcan.ca/english/census01/home/index.cfm> (Version current at November 1, 2006).

22. Dillman DA. Mail and Internet Surveys: The Tailored Design Method, 2nd edn. New York: John Wiley \& Sons Inc, 2000.

23. Statistics Canada. Standard Geographical Classification (SGC) 2001. <www.statcan.ca/english/Subjects/Standard/sgc/2001/2001 sgc-intro.htm $\# 4>$ (Version current at November 1, 2006).

24. Von Korff M, Ormel J, Keefe FJ, Dworkin SF. Grading the severity of chronic pain. Pain 1992;50:133-49.

25. Spitzer RL, Kroenke K, Williams JB. Validation and utility of a selfreport version of PRIME-MD: The PHQ primary care study. Primary Care Evaluation of Mental Disorders. Patient Health Questionnaire. JAMA 1999;282:1737-44.

26. American Psychiatric Association. Diagnostic and Statistical Manual of Mental Disorders, 4th edn. Arlington: American Psychiatric Association, 1994.

27. Catala E, Reig E, Artes M, Aliaga L, Lopez JS, Segu JL. Prevalence of pain in the Spanish population: Telephone survey in 5000 homes. Eur J Pain 2002;6:133-40.

28. Hunter J. Demographic variables and chronic pain. Clin J Pain 2001;17(4 Suppl):S14-9.

29. Mantyselka PT, Turunen JH, Ahonen RS, Kumpusalo EA. Chronic pain and poor self-rated health. JAMA 2003;290:2435-42.

30. Lachapelle D, Hadjistavropoulos T. Age-related differences among adults coping with pain: Evaluation of a developmental life-context model. Can J Behav Sci 2005;37:123-37.

31. Blyth FM, March LM, Cousins MJ. Chronic pain-related disability and use of analgesia and health services in a Sydney community. Med J Aust 2003;179:84-87.

32. Scudds RJ, Robertson JM. Pain factors associated with physical disability in a sample of community-dwelling senior citizens. J Gerontol A Biol Sci Med Sci 2000;55:M393-9.

33. Waldram JB. The aboriginal peoples of Canada: Colonialism and mental health. In: Al-Issa I, Tousignant M, eds. Ethnicity, Immigration, and Psychopathology. New York: Plenum Press, 1997:169-87. 


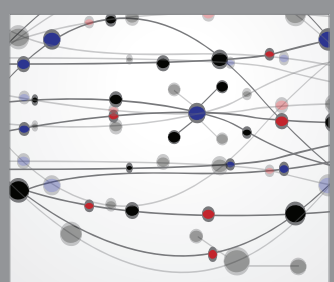

The Scientific World Journal
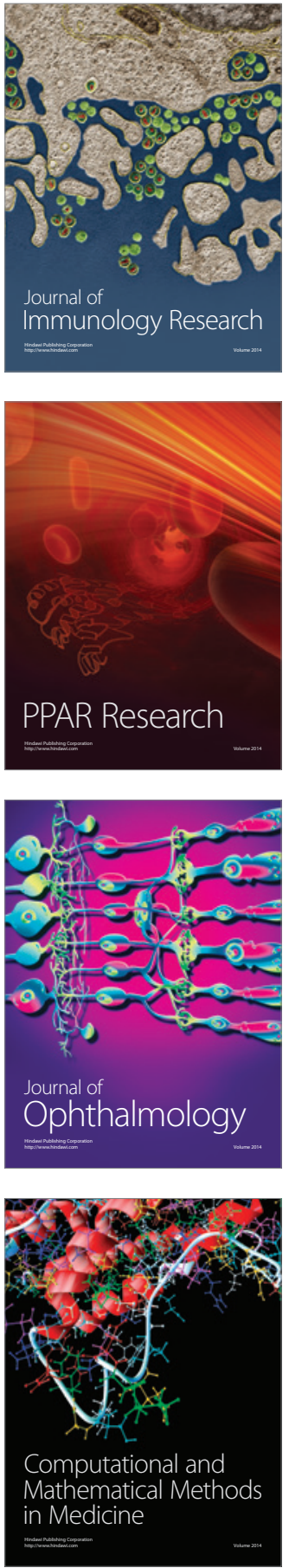

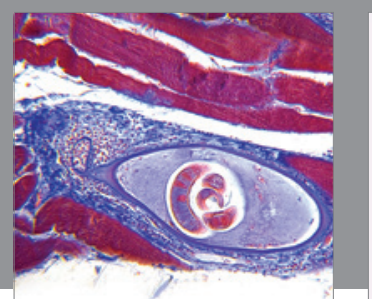

Gastroenterology Research and Practice

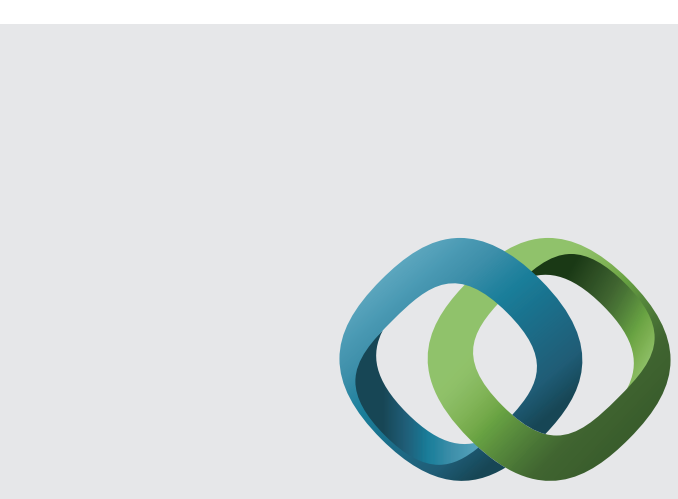

\section{Hindawi}

Submit your manuscripts at

http://www.hindawi.com
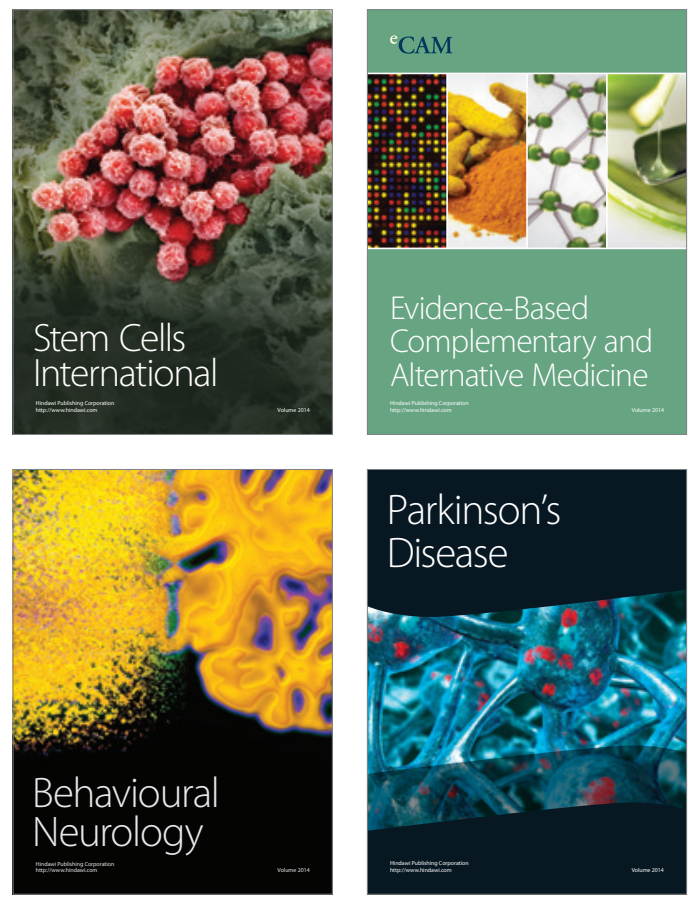
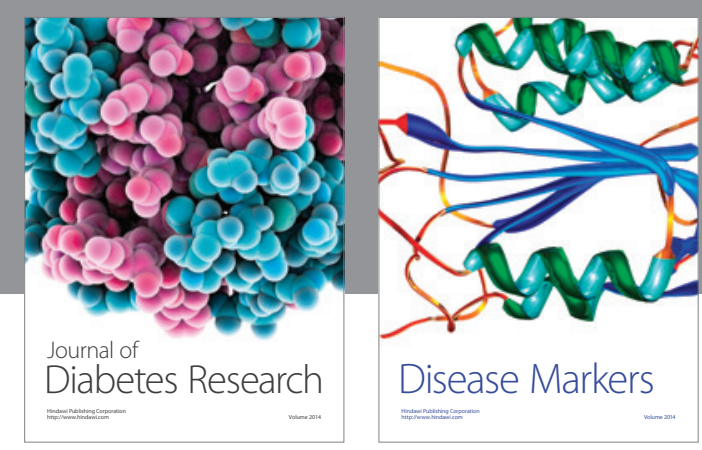

Disease Markers
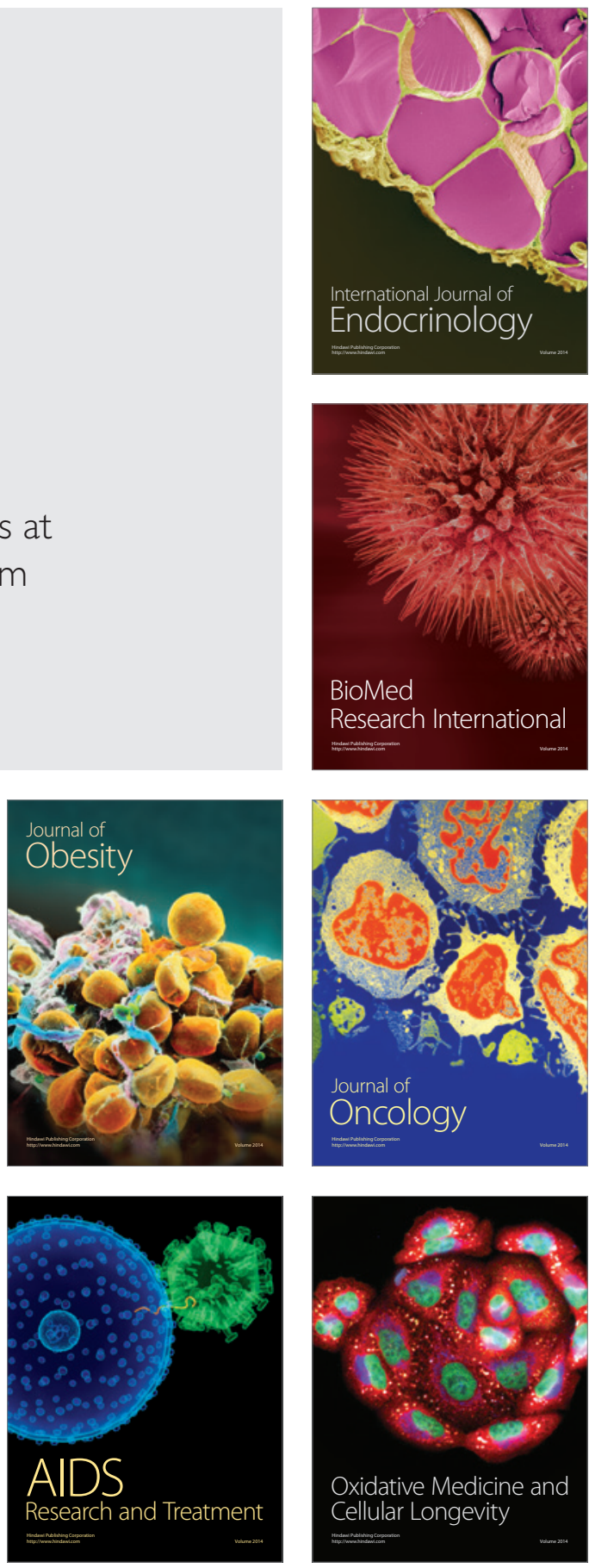